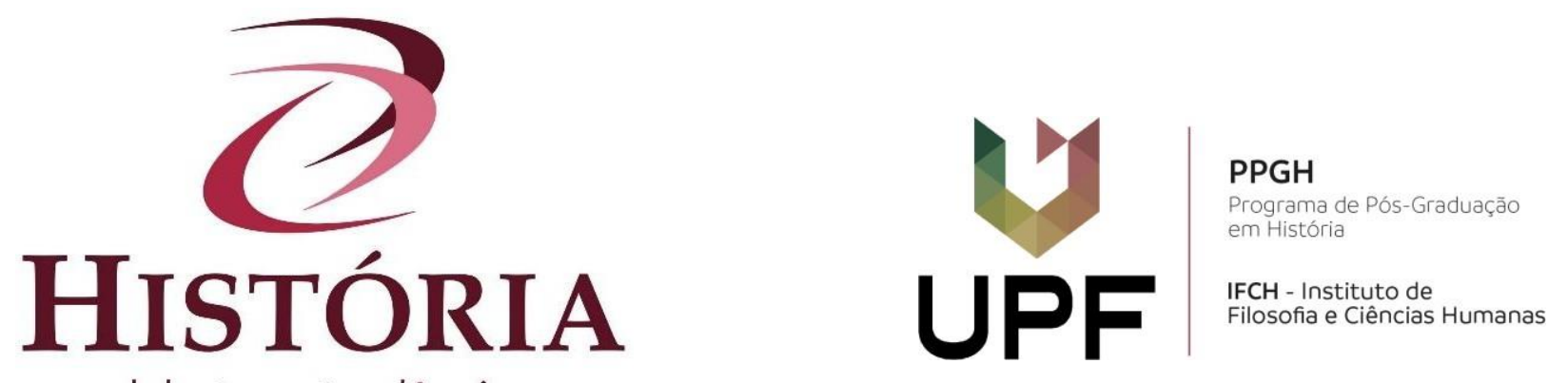

debates e tendências

\title{
Anticomunismo e Inimigo Interno: uma avaliação da Doutrina de Segurança Nacional a partir de sujeitos e manuais da repressão durante as ditaduras do Conesul \\ Anticommunism and Internal Enemy: an assessment of the National Security Doctrine from repression subjects and manuals during the Conesul dictatorships \\ Anticomunismo e Inimigo Interno: una evaluación de la Doctrina de Seguridad Nacional a partir de sujetos y manuales de la represión durante las dictaduras del Conesul
}

Marcos Vinicius Ribeiro ${ }^{\mathrm{i}}$

Resumo: O artigo parte de uma análise teórica-conceitual da historiografia que debate os usos do passado para produzir síntese crítica a respeito das rupturas e permanências de alguns aspectos da construção e adaptação da Doutrina de Segurança Nacional (DSN) para a América Latina, a partir de manuais militares redigidos por interlocutores da repressão (civis e militares) em documentos anticomunistas. Procuramos demonstrar em manuais da repressão e documentos da Confederação Anticomunista Latino-americana (CAL), como a construção do "inimigo interno", produzida durante o período de vigência da política de Terrorismo de Estado (TDE) que caracterizou as Ditaduras de Segurança Nacional, foi articulado e acionado como fórmula de combate e perseguição às oposições durante as ditaduras. Finalizamos o artigo com uma avaliação de conjunto que situa algumas permanências do anticomunismo como elemento orgânico de disputa da hegemonia.

Palavras chave: Anticomunismo. Ditaduras. Repressão.

\begin{abstract}
The article starts from the analysis theoretical-conceptual of historiography that discusses the uses of the past to produce a critical synthesis about the ruptures and permanences of some aspects of the construction and adaptation of the National Security Doctrine (DSN) for Latin America, starting from military manuals written by interlocutors of repression (civilian and military) in anti-Communist documents. We tried to demonstrate in manuals of the repression and documents of the Latin American Anticommunist Confederation (CAL), as the construction of the "internal enemy" produced during the period of the State Terrorism (TDE) policy which characterized the National Security Dictatorships, was articulated and triggered as a formula for combat and persecution of
\end{abstract}


oppositions during dictatorships. We conclude the article with an overall evaluation th at places some permanencies of anti-communism as an organic element of dispute over hegemony.

Keywords: Anticommunism. Dictatorships. Repression.

Resumen: El artículo parte de un análisis teórico-conceptual de la historiografía que debate los usos del pasado para producir síntesis crítica acerca de las rupturas y permanencias de algunos aspectos de la construcción y adaptación de la Doctrina de Seguridad Nacional (DSN) hacia América Latina, a partir de manuales militares redactados por interlocutores de la represión (civiles y militares) en documentos anticomunistas. Buscamos demostrar en manuales de la represión y documentos de la Confederación Anticomunista Latinoamericana (CAL), como la construcción del "enemigo interno", producida durante el período de vigencia de la política de Terrorismo de Estado (TDE) que caracterizó a las dictaduras de seguridad nacional, fue articulado y accionado como fórmula de combate y persecución a las oposiciones durante las dictaduras. Finalizamos el artículo con una evaluación de conjunto que sitúa algunas permanencias del anticomunismo como elemento orgánico de disputa de la hegemonía.

Palabras clave: Anticomunismo; Dictaduras; Represión.

\section{Introdução}

A história e a historiografia das ditaduras de Terrorismo de Estado e Segurança Nacional (PADRÓS, 2005), assim como a história e a historiografia de outros temas e objetos da pesquisa histórica, perpassaram importantes itinerários heurísticos e temáticos conduzidos pela avaliação da historiografia como campo de disputas entre projetos de hegemonia da própria história, revelando-se como direção moral e intelectual de uma classe (GRAMSCI, 2002, p. 62-63), invertendo a relação clássica entre passado-presente (CHESNAUX, 1995, p. 56). Acervos documentais e produções historiográficas, nesse caso, delimitaram-se mutuamente.

Desde o anunciado boom de memória dos anos de 1970, ocasionado pelas ações violentamente encampadas pelos diversos extermínios em massa do século XX, tragicamente representados pelas duas Guerras Mundiais e as crises cíclicas do capitalismo, a historiografia foi acionada para dar explicações a respeito de um passado reificado (TRAVERSO, 2012, p. 11). A memória transformada em produto estetizado, disponibilizada ao consumo nos mais variados suportes (desde museus, séries televisivas, romances editoriais, dentre outros), desafiou o estudo da História recente no mundo ocidental, colocando em segundo plano documentos e hipertextos que, até então, se tratavam dos principais suportes para a escrita da história.

Desde então, os paradigmas tradicionais da historiografia foram problematizados a partir das mais variadas questões, que colocavam na defensiva suas concepções mais tradicionais. Em certa medida, o progresso dos estudos acadêmicos relacionados ao tema das ditaduras dependeu, em maior ou menor grau, da demanda social dos sujeitos históricos 
que procuraram conhecer e reconhecer o passado recente destes regimes políticos e explorar as suas permanências (continuidades) e transformações (rupturas) sob as mais variadas instâncias e circunstâncias, seja na economia, na cultura e/ou nas relações sociais de um modo geral. Destes processos de influências mútuas surgiram novos problemas, hipóteses e objetivos que se renovam constantemente devido ao exercício das relações entre as classes no contexto da construção e reconstrução da política e, por consequência, da própria versão histórica. Nesse caso, presenciamos a construção da história recente em seu caráter inconcluso, terreno em que os problemas, hipóteses, objetivos e temas são sempre provisórios dado o caráter crítico que envolve a heurística do historiador (FRANCO; LEVIN, 2007, p. 50).

A elaboração da percepção histórica acerca das ditaduras militares, por vezes, se confunde com as demandas sociais elaboradas em distintos contextos sociais de crise. A procura pela saída imediata de um determinado contexto de crise, seja ela uma solução política, econômica, ou, até mesmo, de paradigma social e cultural, é capaz de retomar possibilidades de interpretações do passado que atuam como idealização do mito das origens idílica, perdida em meio a avalanche de acontecimentos que são capazes de abalar as estruturas sociais avaliadas, idealisticamente, como estáveis, colocando nosso próprio paradigma da História em crise (FONTANA, 1998, p. 251).

A estas avaliações escapa a noção processual da História, e, com isto, toda a contradição organizada nas diversas formas de construção e reconstrução do passado e da memória que delimitam o horizonte de expectativas (KOSELLECK, 2006) das sociedades e dos sujeitos em direção à este passado. A aquiescência com o mito das origens como refúgio dos traumas presentes gerados pelas vivências da crise parece autorizar interpretações revisionistas e negacionistas acerca do passado recente, por um lado, e outras que se dedicam a transformar o real sentido dos regimes de repressão por outro. Nesse sentido, reside o campo de disputas do passado em relação às ditaduras.

Este movimento de reelaboração do passado trouxe a possibilidade de delineamento de políticas de reparação (VINYES, 2009) que se reproduzem a partir de discursos reverberados nos meios de comunicações a partir dos interesses de classes e de seus interlocutores, e se transformam numa espécie de paradigma rival ao exercício científico da historiografia proposto pelos historiadores, mas num sentido muito diferente da históriadisciplina gestada na tradição metódica e positivista que nasceu "contra a memória", enquadrando uma série de operações metodológicas e críticas que colocavam sob suspeita o passado lembrado e narrado pela tradição oral e pela crônica (NAPOLITANO, 2018, p. 206). 
Este processo produz uma miríade de possíveis interpretações que se esboçam a partir da defesa e celebração de uma determinada posição e situação de classe (BORDIEAU, 2008). As conclusões imediatas a respeito do papel desempenhado pelas ditaduras latinoamericanas, nesse quadro possível de disputas hegemônicas (DIAS, 1996), é esboçado a partir de percepções objetivas de uso da violência no processo político, gerando, inclusive, certa cultura do medo (PADRÓS, 2014, p. 13) no que tange ao testemunho e, por consequência, ao próprio estudo do período. Nem mesmo a defesa do recuo temporal em relação aos acontecimentos pela historiografia tradicional, garantiu ao campo do historiador isenção com relação ao sentido histórico dos acontecimentos, pois em pleno exercício democrático, os diversos movimentos de luta pela memória, verdade e justiça tocaram o ponto nevrálgico da impunidade ditatorial ao reivindicar a aparição com vida de seus entes desaparecidos.

No entanto, o método heurístico e a crítica das fontes permitem ao historiador certo aprofundamento crítico. Portanto, a crítica é a ferramenta histórica que diferencia qualitativamente o trabalho do historiador diante da avalanche de informações pulverizadas nos diversos pontos de vistas que interpretam o período recente de nossa história ao sabor das conjunturas políticas.

Outro fator que influencia diretamente a produção historiográfica acerca dos temas da História do Tempo Presente, em especial sobre as ditaduras, é a disponibilidade de fontes oficiais a respeito do período (KOSELLECK, 2006, p. 292). Trata-se de um problema enunciado por historiadores que só consideram documentos oficiais como fontes históricas legítimas para o estudo das ditaduras e, por consequência, de nosso passado recente. Não se pode apresentar tal problema como óbice definitiva para o estudo deste passado, pois se trata de um passado inconcluso em que sujeitos, protagonistas ou expectadores, enfim, sujeitos históricos, se deparam cotidianamente com este passado (FRANCO; LEVIN, 2007, p. 31). Trata-se de uma das principais características da história do nosso tempo, o fato de serem processos inconclusos, revelando a caráter dinâmico de nossa história como uma história ainda em curso. Portanto, fontes oficiais, relatos orais, reconstruções fílmicas e cinematográficas, comemorações, (des)comemorações, patrimônios materiais e imateriais, denominações de ruas, cidades, escolas, ou seja, uma ampla gama de representações e vivências públicas e privadas são fontes de estudos do passado recente latino-americano no sentido das políticas de reparação e, por vezes, de esquecimento (VINYES, 2009).

Se as conjunturas políticas, por um lado, organizam determinadas demandas sociais em torno dos temas da história recente dos países latino-americanos, em especial, os países do Cone Sul, algumas soluções de colaborações conjunturais também organizaram 
determinadas soluções históricas nos anos de 1960 e 1970 nestes países com contornos políticos de um Terrorismo de Estado (PASCUAL, 2004). Nesse caso, as colaborações repressivo-militares-policiais presentes em iniciativas como a Operação Condor são elucidativas a respeito deste tema. O envolvimento de Argentina, Brasil, Bolívia, Chile, Paraguai, Uruguai e Venezuela em ações conjuntas bilaterais, trilaterais e em reuniões estratégicas, intercâmbio de informação e prisioneiros, a realização de operações coordenadas de ação psicológica e a ação clandestina dos organismos de inteligência além dos limites territoriais de cada país (SLATMANN, 2012. p. 47) são outros delineamentos históricos de processos de interferência direta nas relações sociais de cada caso ditatorial, correspondendo a uma lógica sistêmica de organização de tais ações/processos. Sendo assim, apesar das delimitações nacionais entendidas a partir das especificidades históricas de cada país, as ações conjuntas, ou até mesmo a permissão (por vezes informal) para que agentes da repressão atuassem no exterior, denotam certa combinação de fatores históricos conjunturais de nosso passado recente.

A metodologia repressiva tomada como exemplo dos manuais oriundos da interpretação da Doutrina de Segurança Nacional (estadunidense) e da chamada Guerra Contra insurgente (de inspiração francesa) e aplicadas durante as ditaduras, seguiu o paradigma de definição do "inimigo interno".

Tratava-se, portanto, de uma reestruturação social ampla e irrestrita direcionada às corporações militares. As entidades anticomunistas que atuaram no Cone sul latinoamericano das ditaduras de Segurança Nacional, tentaram fomentar entre seus apoiadores tais preceitos de reestruturação, difundindo, como sugere a historiografia, a luta contra o "inimigo interno" delimitando, assim, a função histórica de tais regimes políticos em torno do exercício efetivo da hegemonia da classe dominante.

Em grande medida, os manuais militares são insígnias deste processo e as transformações ocorridas no treinamento de tais instituições correspondeu às necessidades de sustentação daqueles regimes. Entretanto, não foram só os manuais militares que apresentaram essa expressão da construção do inimigo (interno). Organizações da sociedade civil - algumas delas contaram com funcionários dos órgãos de repressão do Estado, é verdade - também reverberaram tal lógica com o intuito de alarmar as sociedades em tempos de ditaduras, bem como conspiraram para apoiar governos marcadamente anticomunistas. Nesse sentido, o anticomunismo emerge como questão histórica que experimenta certa continuidade em meio as rupturas temporais que seguem o curso da história.

Para situar algumas dessas questões históricas, a seguir, discutiremos alguns indícios dessas continuidades e transformações a partir de alguns manuais, dois deles diretamente 
relacionados ao treinamento repressivo e outro de divulgação interna das premissas anticomunista adotadas pela Liga Anticomunista Mundial (LAM), que contou com suporte e apoio da Confederação Anticomunista Latino-americana (CAL). O manuais que correspondem ao treinamento/instrução de militares são relacionados, respectivamente, ao exército argentino, e outro dos militares franceses aplicados na guerra da Argélia, além de um terceiro que representou o discurso de honra proferido pelo presidente da LAM, o chinês Ku Sheng-Kang, durante o $3^{\circ}$ Congresso da CAL ocorrido no ano de 1977 na cidade de Assunção, Capital Federal do Paraguai. Para fechar o artigo, evocamos algumas premissas de ação proposta pelo ditador brasileiro Humberto Castelo Branco. Detectar as possíveis aproximações entre manuais da repressão e o discurso de Sheng-Kang é um dos objetivos deste artigo.

\section{A Luta Anticomunista Mundial nos Manuais Repressivos}

O anticomunismo delineou traços estruturais das Ditaduras de Segurança Nacional porque se anunciou como principal fator de reorganização de crescimento do Complexo Militar Industrial (CMI) estadunidense no pós-II Guerra (COOK, 1965). Para aprofundar nossa análise sobre este tema, optamos por levantar algumas ações concretas das ditaduras tendo por base a Doutrina de Segurança Nacional (DSN) com foco no anticomunismo. Nesse sentido, o anticomunismo se tornou evidente mecanismo de controle das sociedades nacionais latino-americanas, por meio da construção e aplicação permanente do conceito de “inimigo interno" (PADRÓS, 2005).

A DSN ativou e delineou o Terrorismo de Estado (TDE), sendo que, este último, se transformou na política permanente de relação entre ditaduras e sociedade (DUHALDE, 1999). Segundo Pascual (2004), o TDE é o terrorismo irradiado a partir do Estado e foi aplicado como política de extermínio e intimidação das oposições que pudessem se colocar em desacordo (com potencial ativação da militância dissonante) a este contexto de dominação capitalista em plena Guerra Fria. Sua aplicação visou, sobretudo, o controle das sociedades nacionais do Cone Sul latino-americano sob o pretexto de erradicação do avanço soviético sobre a região, mas serviu, também, como freio ao avanço da Revolução Cubana (PADRÓS, 2005). Sua aplicação, portanto, correspondeu ao TDE, forma política da DSN. Na avaliação de Enrique Serra Padrós, a DSN se dedicou ao delineamento operacional militar e atingiu às sociedades latino-americanas em sua totalidade, e, inclusive, muito além da bipolaridade que caracterizou o contexto de Guerra Fria. Segundo Padrós, a DSN: 


\begin{abstract}
No seu funcionamento, flexibilizou a figura do "inimigo interno" e transformou numerosos setores da população em potenciais inimigos, aumentando o desconcerto, perturbando as situações mais cotidianas, alterando pautas de conduta social e naturalizando formas de controle disseminadas tanto na dimensão pública (espaços escolares, profissionais e lazer), quanto no âmbito privado da cidadania. Além das ações direcionadas a alvos seletivos (a luta armada, os partidos de esquerda, as direções e organizações sociais), sensações de medo e paralisia atingiram a população em geral, através de canais condutores de uma "violência irradiada", o que facilitou a manutenção do status quo (PADRÓS Apud GALLO, 2014. p. 13).
\end{abstract}

Tendo por base a avaliação de Padrós, podemos dizer que, ao partir do contexto de violência/terror/medo irradiado, as ditaduras de Segurança Nacional e de TDE foram campos extremamente propícios para a proliferação de organizações anticomunistas, embora sua base doutrinária correspondeu a síntese de muitas doutrinas históricas e certamente não se restringiu ao campo militar. Mas durante as ditaduras, portanto, o anticomunismo experimentou um salto qualitativo significativo ao se transformar num dos principais elementos de sustentação daqueles regimes que foi amplamente apoiado pelos setores mais conservadores do capital. Pelo menos, o objetivo de dar suporte e apoiar as ditaduras anticomunistas foi o que motivou o aparecimento de entidades anticomunistas coevas aos objetivos das ditaduras. Nelas (ditaduras e organizações anticomunistas) se combinavam elementos das diversas doutrinas estadunidenses, francesas e asiáticas para a ativação de uma militância reacionária que tomou amplos espaços no Estado, mas que também se reuniu e trocou experiências durante os Congressos promovidos pelas entidades ligadas a sociedade civil propriamente dita. ${ }^{\text {ii }}$

O mais amplo experimento da repressão baseado na doutrina da contra-insurgência (essa de inspiração francesa) na América Latina, estratégia contrarrevolucionária aplicada à oposição, foi acionado na Argentina em 1975, mais precisamente na Província de Tucumán, quando o conjunto do Poder Executivo daquele país permitiu a intervenção direta das Forças Armadas para aniquilar a atividade guerrilheira urbana/rural do Ejército Revolucionário del Pueblo (ERP), mesmo antes da Ditadura que combinou TDE e DSN: "Con el fin de 'aislar' a los elementos guerrilleros y evitar todo apoyo de la populación, se 'escarmienta' en los civiles mediante torturas, secuestros y fusilamientos en los poblados cercanos de la zona de operaciones" (DUHALDE, 1999, p. 234).

Esta intervenção violenta e terrorista do Estado revelou um aspecto importante do modelo de repressão que chegou nos anos de 1970 com certa bagagem histórica, sobretudo no que se refere ao contorno institucional que a DSN e o TDE requereram, pois, segundo Duhalde, no caso argentino: "El propio decreto del P.E. [Poder Executivo] contiene los tres aspectos en que basa sus planteamientos el programa de contrainsurgencia enseñado en la Escuela del Panamá: 1) Represión Física; 2) Acción Cívica; 3) Acción Psicológica" 
(DUHALDE, 1999, p. 234).

A "Instrución de lucha Contra Elementos Subversivos", datada de 23 de agosto de 1976, confeccionada pelos militares argentinos, evidenciou o processo repressivo latinoamericano da segunda metade dos anos de 1970. Nesta instrução, que podemos considerar um manual da repressão, é possível avaliar o conceito de "subversão" interpretado pelos militares argentinos que foi rubricado pelo General Roberto Eduardo Viola, que, à época, ocupou o cargo de Presidente da Junta de Publicações do Exército. Posteriormente, Viola foi presidente da ditadura, já em 1981. Segundo o manual, por definição, subversão:

\begin{abstract}
Se entenderá por tal, a la acción clandestina o abierta, insidiosa o violenta que busca la alteración o la destrucción de los criterios morales y la forma de vida de un pueblo, con la finalidad de tomar el poder e imponer desde el una nueva forma basada en una escala de valores diferentes (JUNTA DE PUBLICACIONES DEL EJÉRCITO ARGENTINO, 1976, p. 1).
\end{abstract}

Além da ampla interpretação acerca do conceito de "subversão", este manual definiu a "contra subversão" como elemento de reestruturação da sociedade, e como forma de oposição às transformações que pudessem incorrer no abalo da sociedade capitalista. A lógica binária, pautada na construção de um jogo de oposições simplificadoras - tais como “claro x escuro", "preto x branco", “ordeiro x subversivo", "honestidade x corrupção", "corruptores x salvadores" -, caracterizou esta publicação militar influenciada por conceitos ideológicos difundidos nos treinamentos corporativos durante a Guerra Fria sob a difusão da DSN. Buscou-se alarmar e definir os contornos gerais da ação "contra subversiva" da seguinte forma:

Se entenderá por tal, al conjunto de medidas, acciones y operaciones que desarrollarán las Fuerzas Legales en todos los campos de la conducción nacional, através de sus elementos componentes (Instituciones y organismos del Estado, Fuerzas Armadas, Fuerzas de Seguridad y Fuerzas Policiales), a fin de eliminar las causas y superar las situaciones que hubieran dado origen a la reacción subversiva y neutralizar o aniquilar el aparato políticomilitar del enemigo (JUNTA DE PUBLICACIONES DEL EJÉRCITO ARGENTINO, 1976, p. 1).

Estas ações se basearam na perspectiva direta de combate e foram descritas como “Aspectos básicos de la acción educadora”. Segundo a Instrução:

La acción educadora, que normalmente se concreta através de aspectos ético-espirituales, sociales, técnico-profesionales y fisicos, para lograr una eficiente formación del personal que interviene en operaciones contrasubversivas deberá tener en cuenta básicamente los siguientes aspectos:

a. Las operaciones de contrasubversión deberán tener un carácter eminentemente ofensivo. b. Deberá darse especial importancia a los conceptos de persecución y aniquilamiento.

e. Las características especiales que impone la lucha contra los elementos subversivos, determinan la necesidad de emplear procedimientos y técnicas particulares de combate (JUNTA DE PUBLICACIONES DEL EJÉRCITO ARGENTINO, 1976, p. 1-2).

O treinamento dos militares latino-americanos, proferido pelos comandantes estadunidenses nas escolas de guerra espalhou, pelo subcontinente, uma aura alarmista que 
permitiu à Ideologia de Segurança Nacional (COBLIN, 1980) penetração entre os quadros militares e policiais. Deste modo, foi irradiada a ponto de se tornar um modus operandi descrito em manuais e instruções técnicas. $\mathrm{O}$ anticomunismo, aplicado à definição de "inimigo interno", foi esgarçado a ponto de considerar perigosa toda atividade que pudesse “colocar em risco" a segurança interna dos países que orbitavam em torno dos interesses capitalistas, com especial atenção à educação como forma de contraposição das transformações sociais que pudessem colocar em risco o satus quo capitalista.

A defesa acirrada dos ideais capitalistas não foi uma pauta que se desenvolveu apenas no âmbito das corporações militares. A Liga Anticomunista Mundial (LAM) ${ }^{\mathrm{iii}}$ e a Confederação Anticomunista Latino-americana (CAL), são dois exemplos de organizações anticomunistas que se apropriaram de elementos doutrinários semelhantes aos que encontramos nos manuais da repressão que circularam no métier militar durante as ditaduras de Segurança Nacional e de TDE $^{\text {iv }}$ e que demonstraremos mais adiante.

Ainda sobre a intervenção estadunidense no contexto de reestruturação das sociedades latino-americanas, segundo Tápia Valdez (1980), os EUA reconstruíram sua política de intervenção direcionada à América Latina tendo por princípio o treinamento e suporte militar que foi responsável pela difusão do anticomunismo da seguinte forma: "El peligro comunista, real o falso, no fue catalogado como un problema de carácter nacional, concerniente exclusivamente a la política interna del país en cuestión, sino como un problema de carácter internacional que legitimaba la intervención [estadunidense] en otros países" (TAPIA VALDÉS, 1980, p. 55).

A violação das soberanias nacionais foi condição sem a qual o sucesso da DSN não se efetivaria, e para isso, os militares estadunidenses contaram com a colaboração e ativismo dos militares latino-americanos responsáveis pela aplicação da DSN nos diversos contextos nacionais. Portanto, ao obedecerem à aplicação dos preceitos norteadores da DSN, conjugada com a perspectiva da hegemonia militar estadunidense sobre comandantes e exércitos latino-americanos, passaram a definir o "inimigo interno" (dos EUA, mas nos contextos nacionais latino-americanos) como alvo.

Sua definição correspondeu à imposição das premissas do Departamento de Estado dos EUA durante a Conferência da Organização dos Estados Americanos (OEA) em 1954, ocorrida em Caracas na Venezuela. Nesta ocasião, o secretário de Estado John Foster Dulles, irmão de Allen Dulles que foi diretor e agente da CIA (e ajudou no golpe de Estado de 1954 na Guatemala contra Jocobo Arbenz), pronunciou-se a favor das intervenções militares estadunidenses por meio dos exércitos locais, segundo a hipótese de que: "La dominación o control de las instituciones políticas de cualquier Estado Americano por el 
movimiento comunista internacional [...] constituiría una amenaza para la soberanía e independencia política de los Estados Americanos [...] (BARNET Apud TAPIA VALDÉS, 1980, p. 55).

Juan Bosch denominou esta fase de dominação estadunidense sobre a América Latina de "pentagonismo" (BOSCH, 1968). Segundo o autor, este processo se iniciou durante a II Guerra Mundial, e se alastrou pelo subcontinente no pós-guerra. A partir deste período, o papel das forças armadas foi ressignificado, assim como a perspectiva de exploração imperialista. A partir de então, o alvo da exploração passou a ser as sociedades nacionais, e as forças armadas transformaram-se no gestor da violência que correspondeu ao crescimento demandado pela indústria bélica no bojo de sua expansão. Portanto, é uma violência requisitada pelos setores dominantes da burguesia nacional associada aos interesses imperialistas.

A partir da leitura de Bosch, é possível avaliar que para explorar a força de trabalho nos contextos nacionais, não se usou mais uma intervenção direta e estrangeira, como experimentado durante a $1^{\text {a }}$ Guerra Mundial, mas, sim, uma nova modalidade de intervenção que Bosch denominou de pentagonismo: "El pentagonismo no explota colonias: explota a su propio pueblo." Sendo que: "Efectivamente, no ha cambiado el uso del poder militar; lo que ha cambiado es su finalidad" (BOSCH, 1968, p. 11).

Nesse sentido, algumas modalidades de intervenção foram adaptadas ao contexto do pós-II Guerra, como se pode atestar a partir da avaliação do general francês Roger Trinquier, veterano do exército francês nos processos de descolonização na África e Ásia, especialmente na Argélia e Indochina. A Indochina e a luta de libertação nacional argelina, impuseram derrotas históricas aos franceses, sendo que os EUA substituíram a França na Indochina. A derrota francesa em ambos os casos, foram avaliadas no manual de Contra Insurgência do General Trinquier. Neste manual, é possível perceber a preocupação extremada daquele repressor com as novas formas de luta contra o comunismo que se sucederam àquelas experiências:

La guerra de hoy es el choque de una serie de sistemas - político, económico, psicológico y militar - que tiende a derrocar el gobierno existente en un país para sustituirlo por otro. Para alcanzar esta meta, el agresor explota hasta el límite la tensión interna del país en su parte ideológica, social, religiosa, económica, etc. En otras palabras, usa cualquier conflicto que pueda tener profunda influencia en la población que va a ser conquistada. Hay todavía más; en vista de la actual situación de las naciones, cualquier punto débil que presente un país por muy apartado o falto de poder que sea, siempre es traído por estos grupos a un plan de actualidad, a fin de convertirlo en parte de un conflicto mundial. Y así, impulsado por estos elementos, un asunto de origen secundario, apenas sin importancia, puede transformarse en una cosa grande una vez que generaliza (TRINQUIER, 1981, p. 22).

Em entrevista a jornalista Marie Monique Robin no livro Escuadrones de la Muerte: 
La escola francesa, o general Campagnon, um dos militares franceses que participaram ativamente da aplicação do novo conceito de guerra que produziu a Doutrina de Contra insurgência, mencionou um dado contextual que atestou a reestruturação das táticas intervencionistas adaptadas ao novo contexto de guerra. Segundo Robin (2005), havia a convicção de defender o império por parte daqueles militares. Ao responder uma questão da referida jornalista sobre as diferenças encontradas no contexto indochinês com relação as práticas bélicas da II Guerra Mundial, o general Campagnon mencionou que:

La Segunda Guerra Mundial fue una guerra lineal, con un frente en el que se avanzaba para enfrentar las líneas enemigas y frente con el que se avanzaba para enfrentar las líneas enemigas y hacerlas retroceder. Así se ha liberado Alençon, y después París. Mientras que en Indochina no había un frente, era una guerra en superficie, por lo tanto había enemigos por todos los lados, detrás de uno, adelante, al costado. Estábamos permanentemente en estado de alerta (ROBIN, 2005, p. 33).

De certa forma, ao anunciar a amplitude das ações de ataque a um inimigo que não se posicionava no campo de batalhas mais tradicional, baseado na experiência de tentativa de garantir o controle sobre as colônias africanas e asiáticas, os generais franceses chamaram a atenção para o que veio a se constituir na chamada Guerra Moderna. Sobre esta nova metodologia de ação, adaptada ao contexto que emergiu das lutas populares de libertação nacional em meio ao processo de descolonização, Roger Trinquier alertou para o seguinte contexto:

En la guerra moderna el enemigo no es tan fácil de identificar. No hay frontera física que separe los dos campos. La línea que marca la diferencia entre el amigo y el enemigo puede encontrarse muchas veces en el corazón de la nación, en la misma ciudad donde reside, en el mismo círculo de amigos donde uno se mueve, quizás dentro de su propia familia. Es más bien descubierta si queremos determinar pronto quiénes son en realidad nuestros adversarios y a quienes tenemos que derrotar (TRINQUIER, 1981, p. 41).

Com a luta de classes em níveis alarmantes, insuflada por meio de soluções militares que produziram uma série de golpes de estado durante os anos de 1960-70 e 1980, veio a lume, no caso das ditaduras, a prática de desaparição forçada no que ficou conhecida como a Disposición Final (REATO, 2012). Nesse caso, o inimigo a ser combatido foi identificado com o abalo dos valores ocidentais e cristãos, o que transformou a luta contra a subversão, capitaneada pelas diversas juntas militares e ditadores, em representantes reais e imaginários de uma forma de heroísmo capitalista contra o mal subversivo/comunista.

O general Jorge Rafael Videla, que presidiu a junta militar que deu o golpe de Estado de 1976 e, posteriormente, presidiu a própria Argentina de 1976 a 1981, confirmou a perspectiva salvacionista que os setores econômicos da classe dominante argentina depositaram nos militares. Trata-se de uma diferença fundamental no que se refere a "guerra revolucionária", "guerra moderna" ou "doutrina contra insurgente", já que, com essa, os militares franceses agiram para defender o império. Já na “disposição final”, os valores 
defendidos foram de outra natureza, uma espécie de salvacionismo cruzadista a serviço das reestruturações econômicas neoliberais, que se produziu na indicação do Ministério da Educação. Segundo o jornalista Ceferino Reato:

Ese objetivo coincidía con la opinión del sector empresarial encabezado por José Alfredo Martinez de Hoz, "Joe", quien junto com Ricardo Bruera, fueron los únicos civiles del primer elenco de ministros de Videla. Bruera fue propuesto para Educación por Monseñor Adolfo Tortolo, arzobispo de Paraná, vicário castrense y titular del Episcopado (REATO, 2012, p. 157).

Segundo (PAZ; GONZÁLEZ; PALAU, 2006), o caso paraguaio foi semelhante, mas direcionado a resolução de conflitos políticos que foram avaliados sob o prisma de uma crise institucional permanente, que se estendeu desde o fim da guerra do Chaco contra a Bolívia. Contudo, o processo de redenção ao qual se propôs a instituição militar, ocorreu da seguinte forma:

Desde el final de esta cruenta contienda en la que los militares institucionalistas respaldados por los partidos de oposición (liberal, febrerista y comunista) fueron derrotados por los militares "moringuistas" apoyados por los pynandi colorados, los gobiernos se habían sucedido golpe tras golpe y la falta endémica de instituciones sumía al Paraguay en la miseria y la incertidumbre. Quizás por eso, importantes segmentos políticos del país se aceptaron como un mal menor al advenimiento de una mano militar que pusiera fin al desorden político y pacificara la Republica. (...)

[Stroessner] Desconfiado hasta el extremo, tuvo una habilidad para identificar certeramente primero, y golpear despiadadamente enseguida (...).

La tortura era utilizada de modo rutinario. Los presos eran procesados judicialmente en raras ocasiones. El destierro y el confinamiento eran utilizados con asiduidad para castigar a opositores (PAZ; GONZÁLEZ; PALAU, 2006, p. 53-54-55).

O papel desempenhado pela polícia da capital em relação à repressão e ao TDE, segundo os mesmos autores, residiu na centralidade do combate do "inimigo interno", identificado com os comunistas, e que foi usada para "legitimar" ações de TDE pela Polícia Técnica da Capital, Assunção. Traço marcante das ações repressivas desenvolvidas por $L a$ técnica, a desqualificação dos comunistas virou uma senha de permissividade para sessões de perseguição, captura, tortura e desaparição. Imagem recorrente nos arquivos da polícia paraguaia, o anticomunismo foi avaliado da seguinte forma por Paz, Gonzales e Palau,

El apelativo de "comunista", tan fácilmente endilgado por una Policía que hacía del anticomunismo su justificación fundamental, significaba para el afectado un estigma difícil de borrar. La conservadora y temerosa sociedad paraguaya toleraba más fácilmente los desmanes policiales si éstos se cometían contra "agente del comunismo internacional (PAZ; GONZÁLEZ; PALAU, 2006, p. 102-103).

Foi nesse contexto que se desenvolveu o $3^{\circ}$ Congresso da Confederação Anticomunista Latino-americana (CAL). Em meio a sociedade paraguaia que, segundo os 
referidos autores, tolerava determinadas arbitrariedades se atos de repressão fossem justificados como combate ao comunismo, identificado como um inimigo a ser combatido, independentemente do método ou a medida do uso da violência.

Os Congressos da CAL ofereciam um espaço de interlocução para agentes da repressão (no Paraguai, um de seus membros mais ativos foi o policial e advogado Antonio Campus Alum), empresários (dentre eles o brasileiro Carlo Barbieri Filho), padres e professores. Foi no Congresso de 1977, ocorrido na cidade de Assunção, Paraguai, que o presidente de honra da Liga Anticomunista Mundial (LAM), o chinês Ku Sheng-Kang, proferiu as seguintes palavras:

Si por desgracia la América Latina fuera invadida por las fuerzas comunistas, no solo facilitaría un atajo a los comunistas para atacar la América del Norte, sino que permitiría que los rojos dispongan de una excelente base para lanzar por el flanco un ataque al continente africano. La Rusia Soviética instaló en Cuba hace algunos años bases para el lanzamiento de proyectiles, lo que prueba que los soviéticos pretendían utilizar la América Latina como base avanzada para atacar la América del Norte. Al incitar a los cubanos a invadir Angola y Zaire, los rusos han demostrado que abrigan el propósito de esclavizar a los pueblos latinoamericanos a fin de que les sirvan de instrumentos para agredir a los países libres.

$\mathrm{Al}$ caer en manos del comunismo, Cuba se ha convertido en una cuña peligrosa que facilita la expansión roja en América Latina. Los hechos indican que la plaga roja que amenaza actualmente Latinoamérica tiene su origen en Cuba. La situación estratégica mundial sufrirá un cambio radical si se extendieran los tentáculos comunistas por la América Latina. De ahí la tremenda importancia que tiene para el mundo libre la defensa de la libertad y seguridad de Latinoamérica (SHENG-KANG, 1977, p. 2-3).

A avaliação da conjuntura com forte apelo alarmista caracterizou quase todos os discursos proferidos durante aquele Congresso. No entanto, a visão de conjunto apresentada neste trecho do discurso sugere uma reação veemente em relação ao alcance de uma guerra mundial. Por isso, a tônica das ações anticomunistas exigiriam uma estratégia geopolítica supracontinental, o que, em alguma medida, justificaria cooperações repressivas dedicadas a aniquilação do inimigo comum.

Como se pode observar, a questão geopolítica latino-americana se apresentou como um perigo real e eminente aos países da América do Norte. Nesse sentido, a Revolução Cubana se transformou, pelo menos na hipótese levantada por Sheng-Kang, em um mero entreposto para a dominação soviética. De certa forma, trata-se de uma avaliação pautada na impossibilidade de coexistência entre sistemas econômicos, militares e culturais antagônicos situados na bipolaridade que caracterizou a Guerra Fria.

Outros aspectos da "segurança hemisférica" foram salientados pelo anticomunista chinês em outro trecho de seu discurso:

Vengo de China, país que ha sufrido en carne propia las atrocidades del comunismo; vengo del Asia, continente que ha sido víctima de invasiones rojas. Al asistir hoy a esta conferencia 
de la Confederación Anticomunista Latinoamericana y comprobar la gran solidaridad que existe entre los pueblos de la América Latina oponerse firmemente al comunismo, me siento muy reconfortado. La tragedia de los pueblos asiáticos no debe repetirse en otras zonas de Latinoamérica! No debe permitirse que la libertad y la seguridad de la América Latina sean amenazadas nuevamente por la expansión comunista! Ante todo, mis sentimientos de rendida admiración hacia vosotros que estáis dirigiendo gallardamente la lucha para salvaguardar la libertad y seguridad de este continente (SHENG-KANG, 1977, p. 2).

Ao oferecer formas de avaliação do combate anticomunista nos mais diversos contextos, estes anticomunistas procuravam expressar sua própria visão de mundo, perpassada pelo catastrofismo que demarcou o avanço do inimigo (comunista), e recheado de teorias de segurança continental que, entre outras coisas, não permitiria a coexistência pacífica com o inimigo. Em alguma medida, a hegemonia militar (estadunidense), no contexto social latino-americano, é reconhecida nas palavras de Sheng-Kang, para quem, "No [se] debe permitir que la libertad y la seguridad de la América Latina sean amenazadas nuevamente", e que descreve, mesmo que com pouco destaque, a repercussão da política de TDE e de aniquilação do inimigo, transformando toda a sociedade latino-americana em um enorme campo de repressão. Sempre que avaliaram o comunismo e/ou justificaram o uso da repressão contra o inimigo, os anticomunistas julgaram-nos como representantes do retrocesso, verdadeiros antípodas do desenvolvimento.

O ditador brasileiro Humberto de Alencar Castelo Branco, já advertia, muito antes dos anos de 1970, que a necessidade de adaptação das tropas militares regulares ao novo contexto de combate deveria conjugar fatores de segurança e desenvolvimento. Para Castelo Branco, a força do inimigo residia, justamente, na sua versatilidade e capacidade de operar dentro das fronteiras nacionais, não se limitando, portanto, a uma ameaça externa. Desta forma, segundo o ditador, a relação histórica entre segurança e desenvolvimento significou que:

\footnotetext{
A revolução industrial tornou a guerra muito mais técnica, o que acentuou a importância do desenvolvimento econômico como elemento de segurança. Esta passou a ser uma decorrência da capacidade de mobilização industrial e logística de apoio. E essa técnica atingiu seu apogeu na idade nuclear.

Paradoxalmente, entretanto, condições especiais criadas pelo "equilíbrio do terror" da era atômica, a que referia CHURCHILL possibilitaram por dois motivos uma divergência temporária entre grau de desenvolvimento e potencial bélico.

Primeiramente porque, tornando-se quase impossível uma confrontação nuclear direta, os antagonismos entre as grandes potências se canalizaram para as guerras periféricas, do tipo "guerra de libertação nacional" ou "guerra revolucionária", de qualquer maneira, de guerra localizada.

Estas se baseiam menos na mobilização econômica do que no enrijecimento ideológico da população; reduzem o esforço logístico pela infiltração parasitária na própria comunidade (CASTELO BRANCO, s/d, p. 8-9).
}

O ditador Castelo Branco, citou uma segunda vertente de desestabilização de 
governos e países - estabilidade política, econômica e de segurança são conectadas para evitar o florescimento do comunismo. Nessa segunda vertente, é preponderante o acesso às armas nucleares, como no caso da crise dos mísseis de 1962, protagonizada por Cuba. Mas como a citação acima afere, é a primeira vertente, que usa de métodos "insurgentes", que preocupou este representante e adepto da DSN. Castelo Branco exemplifica esta tática a partir da experiência vivida por estadunidenses e franceses no Vietnã. Por isso, relacionase aos dois interlocutores anteriores, Trinquier e Ku Sheng-Kang.

O segundo método de desestabilização é avaliado a partir da lógica geopolítica do conflito bipolar inerente à competição da Guerra Fria. Para Castelo Branco, trata-se de uma opção mais remota, mas que poderia ser usada pelo comunismo. Nela o uso do arsenal nuclear, não direto, mas emprestado de países tecnologicamente estabelecidos para países menores, é central. O caso da crise dos mísseis de 1962 é o paradigma de transformação do combate convencional para a "resposta flexível”, cuja estratégia é o uso do território aliado (ligado ao campo comunista) para "aterrorizar" e aniquilar territórios inimigos. Segundo Castelo Branco:

O segundo desses paradoxos encontrou ilustração dramática na instalação abortada de misseis nucleares em Cuba, em 1962. Num tipo de guerra convencional, Cuba não apresentaria um problema de segurança para países maiores e mais industrializados como México, Brasil ou mesmo Venezuela. Se, entretanto, lograsse instalar misseis soviéticos em seu território, teria fundamentalmente alterado o balanço de poder na América Latina, pois poderia hipoteticamente aniquilar de surpresa o poderio industrial de vários de seus países (CASTELO BRANCO, s/d, p. 9).

Nesse caso, o estágio de desenvolvimento tecnológico dos países ameaçados não encontra paralelo no país ameaçador. Pelo contrário, a supremacia técnica pode ser abalada por meio do ataque surpresa que só é possível devido às conexões e uso do território por comunistas. A estratégica aliança entre Cuba e URSS apareceu como elemento de desiquilíbrio, pautado no uso das armas nucleares como fator de cesarismo militar.

\section{Conclusão}

$\mathrm{O}$ artigo problematizou o papel desempenhado por determinados usos do anticomunismo em perspectiva histórica para exemplificar um processo de construção ideológica fundamentado na difusão de doutrinas militares que açambarcaram sujeitos, contextos e processos históricos heterogêneos. Por isso, o tema do anticomunismo situado historicamente e heuristicamente no contexto das ditaduras de Segurança Nacional e de Terrorismo de Estado, se mostrou uma importante chave de interpretação que pode ser colocado em perspectiva histórica, mas sem esquecer suas possibilidades presentes.

Com a retomada conservadora após anos de governos populares na América Latina, pode-se dizer que a retomada do anticomunismo foi um dos pilares ideológicos que 
sustentou e sustenta, na atualidade, esse processo histórico em curso. Pode-se mesmo dizer que o horizonte de expectativas dos anticomunistas, ao proliferar teses e análises alarmistas, se transformaram em um ponto de convergência que pode revelar processos passados ainda em curso nas sociedades atuais.

A importância da problematização histórica de tais temas, quais sejam, os da ditadura, anticomunismo, doutrinas militares, organizações e organizadores sujeitos da ação, revela que o passado recente latino-americano continua em disputa. Tensionado pela disputa hegemônica, o passado das ditaduras tem se apresentado como um importante espaço de reflexões (necessárias) acerca das sociedades atuais. Principalmente se levarmos em consideração o ressurgimento de determinadas ideologias que encontram paralelos históricos fortíssimos com a atuação de ditaduras e ditadores. Daí a importância de uma memória política viva e vivida pelos sujeitos, protagonistas ou não, das reconstruções democráticas atuais, principalmente pelos grupos subalternizados e hegemonizados pela realização do poder autocrático das burguesias que impõem pela perspectiva salvacionista e redentora de revisionismos históricos e ações reacionárias no sentido da construção das sociedades futuras.

\section{Referências}

ANDERSON, Scott; ANDERSON, Jon Lee. Inside the League. The schocking exposé of how terrorists, Nazis and Latin American death squads have infiltrated the World AntiCommunist League. Nova York: Dodd, Mead \& Company, 1986.

BOURDIEU, P. A distinção: crítica social do julgamento. 5 ed. São Paulo: Edusp; Porto Alegre: Zouk, 2008.

CASTELO BRANCO, H. A. Desenvolvimento em Segurança. S/D. S/L.

CHESNEAUX, Jean. Devemos fazer tábula rasa do passado? Sobre a história e os historiadores. São Paulo: Ática, 1995.

COMBLIN, J. A Ideologia da Segurança Nacional: O poder militar na América Latina. Rio de Janeiro - RJ: Civilização Brasileira, 1980.

DIAS, Edmundo. Hegemonia: Racionalidade que se faz história. In: O Outro Gramsci. São Paulo: Xamã, 1996.

DUARTE-PLON, Leneide. A Tortura como Arma de Guerra-Da Argélia ao Brasil: como os militares franceses exportaram os esquadrões da morte e o terrorismo de Estado. Rio de Janeiro: Civilização Brasileira, 2016.

DUHALDE, D. L. El Estado Terorista Argentino. Quince años después, una mirada 
crítica. Buenos Aires: Eudeba, 1999.

FONTANA, Josep. História: Análise do passado e projeto social. Bauru, SP: EDUSC,1998.

FRANCO, Marina; LEVIN, Florencia. Historia Reciente: Perspectivas y desafios para un campo en construcción. Buenos Aires: Paidos, 2007.

GALLO, Carlos Artur e RUBERT, Silvania. Entre a Memória e o Esquecimento: Estudos sobre os 50 anos do Golpe Civil-Militar no Brasil. Porto Alegre: Editora Deriva, 2014.

GRAMSCI, Antônio. Cadernos do Cárcere. Volume 5. Rio de Janeiro: Civilização Brasileira, 2002.

JUNTA DE PUBLICACIONES DEL EJÉRCITO ARGENTINO, Instrución de lucha Contra Elementos Subversivos, 1976.

KOSELLECK, Reinhart. Futuro passado: contribuição à semântica dos tempos históricos. Pontifícia Universidade Católica do Rio de Janeiro, 2006.

LOPES, F. The Feathers of Condor, Transnational State Terrorism, Exiles and Civilian Anticommunism in South America. Cambridge: Cambridge Scholars Publishing, 2016.

MACEDONIO, M. N. Historia de uma Colaboración Anticomunista Transnacional: Los Tecos de la Universidad Autónoma de Guadalajara y el gobierno de Chiang Kai-Shek a principios de los años setenta. In: Historia y problemas del siglo XX, Volumen 1, Año 1, 2010 .

MACSHERRY, P. Predatory States, Operation Condor and Covert War in Latin America. Lanham: Rowman \& Littlefield Publishers, Inc., 2005.

MEYSSAN, Thierry. La Liga Anticomunista Mundial, Internacional del Crimen. Disponível em: http://www.voltairenet.org/article123397.html. Acesso em: 20/05/2019.

NAPOLITANO, Marcos. Aporias de uma dupla Crise: história e memória diante de novos enquadramentos teóricos. SÆCULUM - REVISTA DE HISTÓRIA [39]; João Pessoa, jul./dez. 2018.

PADRÓS, Enrique. Como el Uruguay no Hay... Terror de Estado e Segurança Nacional. Uruguai (1968-1985): do Pachecato à Ditadura Civil-Militar. 2005. 2 v. 875 f. Tese (Doutorado em História) - Programa de Pós Graduação em História, Universidade Federal do Rio Grande do Sul, Porto Alegre, 2005.

PASCUAL, A. L. Terrorismo de Estado: a Argentina de 1976-1983. Brasília: Editora UNB, 2004.

PAZ, A. B.; GONZÁLEZ, M.; PALAU, R. Es mi Informe - Los archivos secretos de la Policía de Stroessner. 5a . ed. Assunción: Servilibro, 2006.

REATO, C. Disposición Final: La confesión de Videla sobre los desaparecidos. Buenos Aires: Sudamericana, 2012.

ROBIN, M. M. Escuadrones de la muerte, la esculea francesa - $1^{\mathrm{a}} \mathrm{Ed}-$ Campana, Argentina, 2014. 
SLATMAN, Melisa. Terrorismo de Estado y Exilio: hipótesis exploratorias para una comparación entre los casos chileno y argentino. Jornadas de Trabajo Exilios Políticos del Cono Sur en el Siglo XX, La Plata, 26-28 sep. 2012.

SHENG-KANG, Ku. La Lucha Contra el Comunismo em Latinoamerica y la Mision de La Confederación Anticomunista Latinoamericana. Asunción, 28 de marzo de 1977.

TAPIA VALDÉS, J. A. El Terrorismo de Estado: La Doctrina de la Seguridad Nacional en el Cone Sur. Ciudad de Mexico: Editorial Nueva Imagen S.A., 1980.

TRAVERSO, Enzo. O passado, modos de usar: história, memória e política. Lisboa: Edições Unipop, 2012.

TRINQUIER, Roger. La Guerra Moderna. Buenos Aires: Ediciones Cuatro Espadas. $2^{\mathrm{a}}$ Edição, 1981.

VINYES, Ricard. El Estado y la Memoria: Gobiernos y ciudadanos frente a los traumas de la historia. Buenos Aires: Del Nuevo Extremo: RBA (Espanha), 2009.

Recebido: 30/05/2019

Aceito: 01/07/2019

Publicado: 04/09/2019

\section{Notas}

\footnotetext{
${ }^{\text {i }}$ Professor da Universidade Estadual de Goiás, Campus de Quirinópolis. Doutor em História pela UNIOESTE-PR, Campus de Marechal Cândido Rondon. E-mail: marcosvhistoria@ gmail.com

ii A Liga Anticomunista Mundial (LAM), fundada em Taiwan, na cidade Taipei no ano de 1966 já era o resultado da iniciativa orgânica do anticomunismo asiático que foi organizado em torno da Liga Asiática Anticomunista ainda nos anos de 1950. Até os anos de 1970, a LAM contou com 12 Congressos realizados pelo mundo. Já a Confederação Anticomunista Latino-americana (CAL) foi fundada em 1972 na Argentina e teve a sua primeira reunião formalizada no mesmo ano na Cidade do México. Até 1977 contou com 3 Congressos, sendo que o último deles foi realizado na cidade de Assunção, Paraguai. O Archivo del Terror localizado em Assunção, no Palácio de Justiça do Paraguai, reúne documentação expressiva de ambas as organizações.

iii A Liga Anticomunista Mundial (LAM), constituída na Ásia em 1966, iniciou seus trabalhos na América Latina no ano de 1972 quando ajudou a fundar no subcontinente a Confederação Anticomunista Latinoamericana (CAL). Sobre ambas as organizações, $C f$.: ANDERSON, Scott; ANDERSON, Jon Lee. Inside the League. The schocking exposé of how terrorists, Nazis and Latin American death squadshave infiltrated the World Anti-Communist League. Nova York: Dodd, Mead \& Company, 1986. LOPES, F. The Feathers of Condor, Transnational State Terrorism, Exiles and Civilian Anticommunism in South America. Cambridge: Cambridge Scholars Publishing, 2016. MACEDONIO, M. N. Historia de uma Colaboración Anticomunista Transnacional: Los Tecos de la Universidad Autónoma de Guadalajara y el gobierno de Chiang Kai-Shek a principios de los años setenta. In: Historia y problemas del siglo XX, Volumen 1, Año 1, 2010. MACSHERRY, P. Predatory States, Operation Condor and Covert War in Latin America. Lanham: Rowman \& Littlefield Publishers, Inc., 2005. MEYSSAN, Thierry. La Liga Anticomunista Mundial, Internacional del Crimen. Disponível em: http://www.voltairenet.org/article123397.html. Acesso em: 20/05/2019.

iv O chamado Archivo del Horror, localizado no Palácio de Justiça do Paraguai na cidade de Assunção, Capital Federal do país, além de um conjunto expressivo de documentos que versam sobre os métodos de cooperação entre polícias para a estruturação da Operação Condor, também guarda documentação expressiva da Liga Anticomunista Mundial (LAM) e Confederação Anticomunista Latino-americana (CAL).
} 